\title{
Os itinerários do MERCOSUl Cultural: Dilemas Para a terRitorializaÇão das Missões Jesuíticas-Guaranis
}

\author{
THE CULTURAL ROUTES OF MERCOSUR: \\ DILEMMAS FOR THE TERRITORIALIZATION OF JESUIT MISSIONS
}

Rodrigo R. H. F. Valverde(*)

\begin{abstract}
Resumo: Os itinerários culturais Jesuíticos-Guaranis são as primeiras políticas culturais do MERCOSUL que foram projetadas e aprovadas para ganhar dimensão territorial e gestão conjunta nos próximas anos. Se os documentos e portarias do MERCOSUL são enfáticos em sugerir que a identificação desses itinerários deve ser pensada como uma estratégia de desenvolvimento local, inclusive econômico, a territorialização dessas decisões ainda se mostra difícil. Os conflitos materiais e simbólicos dessa área de fronteira ainda fragmentam os possíveis efeitos integradores das políticas patrimoniais e das indústrias culturais. Este artigo sugere uma revisão dos documentos que promovem a integração cultural do MERCOSUL, assim como as cartas e declarações de agentes econômicos e sociais que expõem as dificuldades de territorialização.
\end{abstract}

Palavras-chave: Territorialização. Missões, Itinerários culturais. MERCOSUL, Políticas culturais.

\begin{abstract}
The Jesuit Cultural Routes are the first cultural policies projected and approved by MERCOSUR that have an territorial dimension and a demanding for co-management. If the official letters and declarations of MERCOSUR emphasizes that the identification of these Routes should be thought as a strategy of local development, including economic growth, the territorialization of these decisions are still difficult. The symbolic and material conflicts in this frontier area are fragmenting the possible integrating effects of heritage policies and cultural industries. This article suggest a revision of the official documents that promote the cultural integration of MERCOSUR as well as the open letters and manifestations of social and economic agents that reveal the problems to the territorialization.
\end{abstract}

Key-words: Territorialization. Missions, Cultural routes. MERCOSUR, Cultural policies.

${ }^{*}$ ) Professor do Departamento de Geografia_FFLCH/USP.E-mail:<rvalverde@usp.br>. Recebidoem 01.09.2012 eaceito em 15.10.2012. 


\section{INTRODUÇÃO}

As missões Jesuíticas-Guaranis são reconhecidas desde o século XX como Patrimônio Histórico e Cultural da Humanidade da UNESCO e, mais recentemente, tem sido pensadas como eixos de uma política de patrimonialização supranacional do MERCOSUL, além de uma via fundamental para o desenvolvimento econômico e social de áreas de fronteira (FIGURA 1). Todos esses valores parecem ganhar lugar dentro das discussões sobre os itinerários culturais que têm sido realizadas sistematicamente nos encontros dos Ministros e Secretários de Cultura do MERCOSUL nos últimos 15 anos.

Tomamos aqui a concepção de itinerário tal qual esta foi introduzida pela UNESCO em parceria com várias instituições latino-americanas, entre elas o MERCOSUL, com manifestada intenção de servir de orientação para o projeto dos Itinerários Culturais na região. Nesse sentido, para que esse artigo possa ser devidamente compreendido, a ideia de itinerário não deve ser confundida com uma perspectiva individual ou com uma intervenção realizada por um único órgão público de um Estado. De acordo com a carta da UNESCO:

"Un itinerario cultural se convierte frecuentemente en una trama de caminos que, si bien pudo tener un eje central, el trayecto seguido pudo desplazarse en diversos puntos a lo largo del tiempo y a la capacidad de conocimiento del territorio de esta forma su desarrollo en el tiempo y en el espacio perite una interpretación más precisa de la historia. Muchas veces la pérdida total o parcial de tramos o huellas del trayecto, lleva a la fragmentación del mensaje cultural y la lectura sistémica del territorio." (UNESCO, 2009: p. 4)

\section{FIGURA 1 - Os Trinta Povos das Missões}

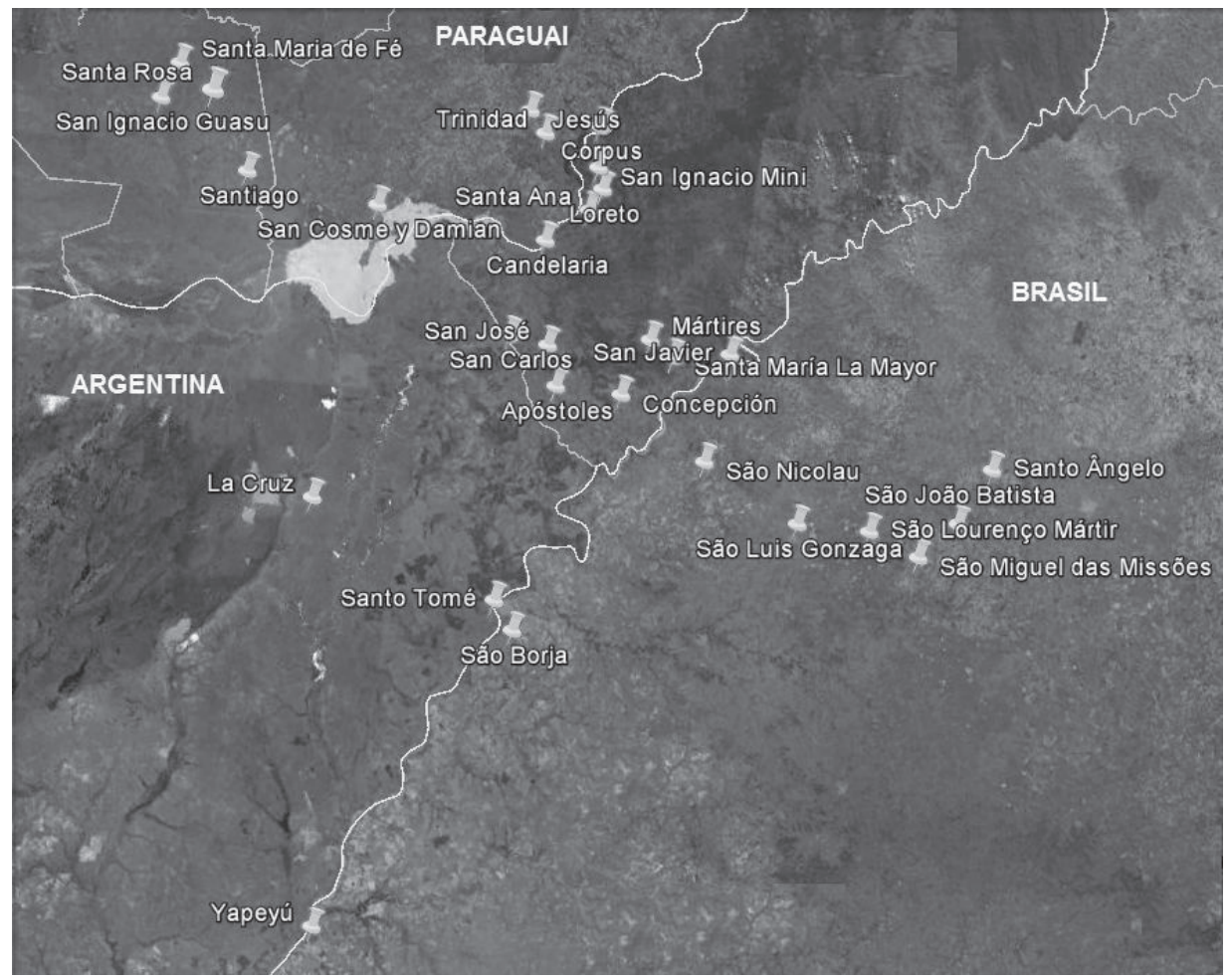


É necessário igualmente salientar que a Geografia possui alguma experiência prévia em estudos desse tema e com objetivos semelhantes. Entre outros, é possível citar a obra de Capel (2005), que enfoca itinerários culturais marcados pelas fortificações no Pacífico Sul, além de chamar atenção para heranças culturais ali existentes. Se somarmos as políticas culturais da UNESCO a esses trabalhos de Geografia desenvolvidos, é possível perceber que o modelo de referência para análise e desenvolvimento da integração cultural no MERCOSUL se encontra indiscutivelmente influenciado pelos limites de discussão do Patrimônio Cultural europeu. Dito de forma mais clara, a ideia de itinerário cultural depende fortemente do debate da autenticidade e da historicidade dos grupos sociais, da estabilidade das formas materiais e da harmonia entre o material e o imaterial.

Nas palavras de Capel:

"Con ello se pone énfasis no solo en los valores culturales o históricos de determinados espacios y paisajes, sino también en 'los movimientos de población, el encuentro, el diálogo, el cambio y la interfecundación de las culturas en el espacio y en el tiempo', a la vez que se insiste en la importancia que tienen esos itinerarios 'para la comprensión mutua, la lectura plural de la historia y la cultura de la paz."' (CAPEL, 2005.)

Dois conceitos geográficos podem ser interessantes para analisar a concretização de uma das primeiras políticas culturais do MERCOSUL: o conceito de território e o conceito de territorialidade. Ambos os conceitos são essenciais para se discutir o modo pelo qual qualquer política se concretiza e se projeta sobre o espaço, redefinindo o acesso aos recursos, aos serviços e às ideias. De acordo com Gomes (1997), o conceito de território é melhor compreendido como:

"uma classificação, não simplesmente uma classificação de coisas, mas de coisas dentro de um espaço. Visto desta forma, o território é definido pelo acesso diferencial do qual ele é o objeto, por uma certa hierarquia social do qual ele é a representação e finalmente por um certo exercício do poder do qual ele é produto e um dos principais instrumentos. A noção de território na geografia moderna fez assim emergir com força a reflexão sobre o poder referenciado ao controle e à gestão do espaço." (GOMES, 1997: p. 49-50.)

De modo análogo, Haesbaert (2007) acrescenta que o debate sobre o conceito de território deve ser compreendido não apenas pela ação de um único agente hegemônico, mas pela existência de múltiplas vozes e poderes dentro de um mesmo limite territorial. De acordo com o autor, por vezes, esses múltiplos poderes coexistem em uma relação de dominação, mas, em outros casos, se colocam em situação de competição ou de conflito, podendo gerar novos cortes territoriais. Nas palavras do autor:

"Enquanto continuum dentro de um processo de dominação e/ou apropriação, o território e a territorialização devem ser trabalhados na multiplicidade de suas manifestações — que é também e, sobretudo, multiplicidade de poderes, neles incorporados através dos múltiplos sujeitos envolvidos (tanto no sentido de quem sujeita quanto de quem é sujeitado, tanto no sentido das lutas hegemônicas quanto das lutas de resistência — pois poder sem resistência, por mínima que seja, não existe). Assim, devemos primeiramente distinguir os territórios de acordo com aqueles que os constroem, sejam eles indivíduos, grupos sociais/culturais, o 
Estado, empresas, instituições como a Igreja etc. Os objetivos do controle social através de sua territorialização variam conforme a sociedade ou cultura, o grupo e, muitas vezes, com o próprio indivíduo." (HAESBAERT, 2007: p. 22)

Tais registros sobre o conceito de território se mostram decisivos, pois ajudam a quebrar o senso comum que confere ao território o sentido de uma ordem jurídica estável, imóvel, com um único grupo de poder e compreendido como um substrato material sem importância para a qualificação dos fenômenos que ocorrem em seus limites. Do ponto de vista da Geografia:

"Todo território é, ao mesmo tempo e obrigatoriamente, em diferentes combinações, funcional e simbólico, pois as relações de poder têm no espaço um componente indissociável tanto na realização de 'funções' quanto na produção de 'significados'. (...) todo território "funcional" tem sempre alguma carga simbólica, por menos expressiva que seja, e todo território "simbólico" tem sempre algum caráter funcional, por mais reduzido que pareça." (HAESBAERT, 2007: p. 23)

Por sua vez, o conceito de territorialidade que trabalhamos é tributário à obra de Sack, que o apresenta da seguinte maneira: "Territoriality is best understood as a spatial strategy to affect, influence or control resources and people, by controlling área; and, as a strategy, territoriality can be turned on and off. In geographical terms it is a form of spatial behavior." (SACK, 1986: p. 1-2) As territorialidades refletem esforços dos mais diferentes agentes para influenciar ou controlar o comportamento de outros, ou então para controlar o acesso a recursos (GOMES, 1997; HAESBAERT, 2007; SACK, 1986). Nem sempre a territorialidade vem acompanhada de estabilidade de domínio sobre o território: em muitos casos, as territorialidades mais agressivas e ativas são aquelas que almejam alcançar uma influência ainda não atingida. Ao promover uma territorialidade, os agentes sociais demonstram que não experimentamos o mundo de forma totalmente passiva, uma vez que tentamos dotá-lo de significados. Para tanto, as territorialidades poderiam se constituir pelo controle do acesso de outros ao território ou pela defesa da exclusividade de certas representações identitárias (símbolos, línguas etc.) sobre os limites territoriais (GOMES, 1997: 46).

Esses conceitos são importantes para o estudo da implementação dos itinerários culturais no MERCOSUL porque a concretização das cartas e documentos das rotas Jesuíticas-Guaranis se mostra lenta e quase emperrada, apesar dos esforços sistemáticos realizados ao longo dos últimos 15 anos. De fato, toda a retórica acumulada em uma série de documentos, na criação de uma base institucional que conecta os serviços de cultura dos diferentes países e na realização de encontros periódicos para a discussão do projeto têm se mostrado pouco efetiva. Acreditamos que isto ocorre justamente pela dificuldade em se definir os marcos de gestão e de planejamento do Itinerário, ao mesmo tempo em que se harmonizam as territorialidades.

Para salientar os desafios da implementação do itinerário cultural jesuítico-guaranis, sugerimos a exploração de portarias, decisões, atas de reuniões, anteprojetos e outros documentos públicos acumulados no MERCOSUL e em outras instituições de 
nível regional ou local. Procuraremos nesses documentos os registros da dificuldade para a territorialização de uma ideia que se mostrou consensual em seu plano retórico, mas cuja implementação se mostra problemática por uma série de aspectos. Ao fazê-lo, esperamos demonstrar que aquilo que falta ao MERCOSUL para o desenvolvimento de políticas culturais efetivas não é exatamente a carência de recursos ou o desinteresse, mas sim uma certa capacidade de pensar territorialmente a sua implementação.

\section{Do itinerário cultural da UNESCO às políticas culturais do MERCOSUL: os desafios da territorialização}

Uma dificuldade frequente para o desenvolvimento de políticas patrimoniais e culturais nos países latino-americanos que seguem o modelo implementado na Europa se refere ao questionamento da autenticidade de seus bens e da viabilidade técnica. Por essa visão, seria preciso admitir que os países latino-americanos teriam inúmeros impedimentos para a concretização de suas políticas culturais e patrimoniais: seus sítios arqueológicos não teriam sido ainda suficientemente mapeados e boa parte foi destruído na expansão da malha urbana que se observou durante o século XX; antigos prédios e sítios teriam sido demolidos e substituídos por outros, sem maiores preocupações em registrar suas localizações e características; as tradições populares sofreram igualmente pela defesa de uma identidade nacional associada à modernização e à padronização, perdendo assim uma parte significativa da sua ligação com a vida cotidiana; os grupos tradicionais resistentes foram isolados em áreas deterioradas; as áreas de fronteira, que muitas vezes concentram potenciais objetos de políticas culturais, se mostram malservidas por redes técnicas, com problemas de acesso e com enorme vulnerabilidade social de sua população. Dentro desse quadro, o patrimônio material tende a se deteriorar, as indústrias culturais (turismo, artes, mercados populares, audiovisual, festas, eventos, moda etc.) encontram problemas para se instalar e promover as suas realizações, enquanto o patrimônio imaterial se coloca em risco de desaparecimento. Como então proceder para que a América Latina e, mais particularmente, o MERCOSUL seja capaz de conservar as suas tradições, ligá-las ao mundo moderno, ao mesmo tempo em que estimula as produções culturais mais atuais e as coloca em ação mediante uma economia criativa?

Em reunião técnica relativa ao Projeto dos Itinerários Culturais do MERCOSUL e contando com assessoria da UNESCO, toma-se como princípio geral de ação que tais itinerários devem necessariamente estabelecer uma relação entre o novo e velho, entre o moderno e o tradicional, entre o material e o imaterial para que se justifique. Não bastaria então localizar os resquícios de um passado, tampouco se esperaria, de acordo com o documento, que as práticas sociais valorizadas pelo MERCOSUL fossem apenas aquelas que seguissem perfeitamente um certo olhar idealizado do passado. Dito de forma mais clara, a ideia de autenticidade deveria então ser ponderada por aspectos mais contemporâneos. Nos termos do documento:

"Los senderos que fueron recorridos originalmente por los antiguos habitantes y los colonizadores de América que se establecieron para efectuar sus transacciones comerciales y su subsistencia básica, hoy han adquirido un valor agregado, debido, en gran parte, a nuevas funcionalidades y significados. Se considera, por lo tanto, que la dinámica de la apropiación 
social del territorio que va imprimiendo nuevos usos y simbologías es un valor cultural tan importantes como los originarios y que se agregan a los preexistentes en un continum" (UNESCO, 2009: p. 7-8.)

Nesse momento, cabe informar que o debate sobre a ideia de cultura que é realizado nos documentos do MERCOSUL Cultural não se apresenta apenas pela dimensão subjetiva, pela defesa da tradição ou pelo clamor da diversidade. Esses aspectos são ponderados pela ideia de que a cultura deve ser vista em convergência com o desenvolvimento econômico local e que, em última instância, a cultura deve contribuir para a real integração do Bloco, ainda que sem impor um modelo único de representação cultural. De acordo com os documentos do MERCOSUL, a cultura tem uma responsabilidade que ultrapassa a erudição ou o simples rigor técnico da conexão com as formas e os significados que eram válidos na América do Sul de séculos atrás. Por sua pretensão territorial, a cultura promovida nos documentos do MERCOSUL deve ser capaz de gerar atividades econômicas, de promover coordenações políticas e sugerir novas formas e comportamentos sociais para a região. Somente assim seria possível ao mesmo tempo promover o desenvolvimento econômico e territorial local, valorizar representações do passado, lidar com os rigores do mundo contemporâneo e criar novas representações que reforcem em plano produtivo e ideológico a integração do Bloco. Breve, as políticas culturais do MERCOSUL devem contribuir para a territorialização:

[considerando] "Que o novo papel que a cultura na agenda internacional constitui um elemento estratégico na formulação das políticas de desenvolvimento regional contribui para aprofundar a integração; Que o reconhecimento de que os bens e serviços culturais possuem dupla dimensão, por gerarem riqueza e serem portadores de identidade, com base na diversidade cultural, contribuem para afirmar o sentido regional; A importância de que o MERCOSUL conte com uma instância permanente de articulação das políticas culturais da região." (MERCOSUL/CMC, 2012.)

De forma ainda mais direta, a Decisão n. 11/1996 do MERCOSUL sugere que ao compromisso já consolidado da redução das barreiras alfandegárias deve se somar a responsabilidade de gestão e de produção cultural por parte do Bloco. Não se trataria então apenas do reconhecimento da diversidade das culturas geridas e pensadas nacionalmente, mas de uma ampliação deste universo para contemplar a coprodução cultural com interferências de agentes supranacionais e locais. Tal qual o texto nos apresenta, seria preciso, entre outras ações, promover diretamente a criação de espaços culturais e de eventos de intercâmbio, o que registra uma mudança em relação a um momento do final do século XX no qual o Estado e os poderes públicos pareciam unicamente se colocar como financiadores ou como agentes passivos diante da discussão da cultura:

"Conscientes de que a integração cultural constitui um elemento primordial dos processos de integração e que a cooperação e o intercâmbio cultural geram novos fenômenos e realidades; Inspirados no respeito à diversidade das identidades e no enriquecimento mútuo; Cientes de que a dinâmica cultural é fator determinante no fortalecimento dos valores da democracia e da convivência nas sociedades; Os Estados Partes comprometem-se a promover a cooperação e o intercâmbio entre suas respectivas instituições e agentes culturais, com 
o objetivo de favorecer o enriquecimento e a difusão das expressões culturais e artísticas do Mercosul. (...) Os Estados Partes facilitarão a criação de espaços culturais e promoverão a realização, prioritariamente em co-produção, de eventos culturais que expressem as tradições históricas, os valores comuns e as diversidades dos países-membros do Mercosul." (MERCOSUL/CMC, 2012.)

O itinerário cultural surge então como a possibilidade de estimular trocas em áreas de fronteira, de fortalecer redes técnicas compartilhadas, de gerir conjuntamente os efeitos das ações sobre as populações locais e de redefinir os limites dos espaços a sua volta. Para tanto, o turismo cultural assume o centro da territorialização, com todos os problemas e desafios que este estabelece.

"El desarrollo del Proyecto de Itinerarios Culturales del MERCOSUR busca atender la necesidad de producir conocimiento acerca de bienes de valor patrimonial, resultantes de procesos históricos, a través de ciclos económicos, en diversos ecosistemas compartidos por los países de la Región, a fin de legitimarlos y certificarlos como destinos patrimoniales, es decir, destinos turísticos culturales." (UNESCO, 2009: p. 6-7.)

Nesse mesmo sentido, Negrete argumenta que as Missões e seus itinerários:

"Condensam muito mais do que pedras gravadas ou peças arquitetônicas, são um resumo do trabalho infatigável e os sonhos de missioneiros Jesuítas e Guaranis de desenvolver uma cultura própria e plena e que, somada a cada particular desenvolvimento dos atuais Trinta Povos, oferecem um recurso cultural e turístico único para a região que abrange estes países irmãos" (NEGRETE, 2005: p.5).

Mais especificante, o projeto dos itinerários culturais no MERCOSUL parece seguir os princípios sugeridos por Pesavento (2007), que sugere a necessária territorialização em seu texto. Nas palavras da autora, é preciso conectar o passado ao presente, os grandes registros materiais do passado às redes e identidades, os registros de uma cultura erudita e francamente nacionalizada a outras representações culturais e populares:

"Missões, um espaço no tempo, é terra de fronteira que ultrapassa a territorialidade dos marcos nacionais. É paisagem de memória que remete a registro no tempo, desde a imagem visual que se oferece ao olhar às imagens mentais, que são em parte sociais e herdadas, e em parte pessoais, fruto da vivência de cada um." (PESAVENTO, 2007: p. 51-52.)

Para que sejam aproveitadas as oportunidades desse projeto, entre outros presentes no MERCOSUL Cultural, são enumerados diversos recursos necessários à territorialização. Em primeiro lugar, se fez necessário a definição de Comissões Regionais dos Países, voltadas especificamente ao caso dos itinerários culturais. Os documentos do MERCOSUL Cultural mencionam igualmente a urgência na realização de um inventário amplo de bens, ruínas e manifestações culturais que podem ser associadas à política dos itinerários culturais. Terceiro, os documentos do MERCOSUL Cultural são enfáticos em relação à necessidade de promoção dos recursos turísticos por diferentes suportes midiáticos. Há também compromissos firmados para a melhoria da acessibilidade da área e 
da infraestrutura e de serviços, além de ratificações da abertura de linhas de crédito para sustentar novos projetos na área. Por último, se coloca que a territorialização depende também da formação de recursos humanos capacitados para a exploração do turismo ou da economia da cultura nessas localidades. Todas essas medidas, previstas em documentos, iniciadas e não concluídas, podem conferir a efetividade do território dos itinerários culturais das Missões Jesuíticas-Guaranis, ao dotar o terreno de melhor acessibilidade, de um controle comum e de uma rede de serviços capaz de unir seus diferentes pontos. No entanto, algumas barreiras concretas e simbólicas ainda impedem o pleno desenvolvimento de sua política cultural (NOGUEIRA, 2007).

\section{O descompasso jurídico, os conflitos simbólicos e a falta de balizas teóricas para a territorialização}

Os problemas de Aduana se mostram relevantes como barreiras à territorialização da cultura na região das missões. Ainda que se considere o esforço para promover a integração por intermédio da criação do primeiro Centro Unificado de Fronteira (CUF), entre São Borja (Brasil) e Santo Tomé (Argentina), os efeitos práticos ainda parecem pequenos. O CUF reúne:

\footnotetext{
“(...) a totalidade dos organismos públicos argentinos e brasileiros responsáveis pela nacionalização e liberação de veículos e mercadorias. Os organismos binacionais, inclusive, utilizam o mesmo prédio: Aduana Argentina, Gendarmeria Nacional Argentina, Banco de la Nación Argentina, SENASA, Câmara Argentina de Comércio, INAL, Receita Federal, Polícia Federal, Banco do Brasil, Ministérios da Agricultura e Saúde, Agência Nacional de Transportes Terrestres - ANTT, EMATER, Associação Comercial e Industrial de São Borja — ACISB, entre outros." (ADUANA BRASIL, 2007.)
}

A parceria público-privada multinacional para gestão do CUF elegeu a empresa MERCOVIA, consórcio multinacional, após edital internacional. Se por um lado houve a concentração dos serviços de aduana em uma mesma área, os efeitos dessa concentração ainda se mostram tímidos. O aumento da atividade comercial apenas acompanhou os movimentos do comércio internacional. Não houve polarização de turistas para esse ponto da fronteira e não se notaram efeitos maiores para as políticas culturais da região. Para que a lentidão do serviço de aduana possa ser superada, falta orçamento próprio ao CUF. Teme-se que o fim do contrato de concessão possa ter como consequência a quebra do acordo internacional, sobretudo em um momento de estagnação comercial do MERCOSUL. Também se nota que o efeito do primeiro CUF foi restrito na medida em que ainda existem outras saídas de fronteira. De uma forma geral, é possível afirmar que o desenvolvimento de uma integração maior, inclusive no que se refere à política cultural, depende de uma harmonização de leis e procedimentos fiscais. Não basta concentrar todas as atividades de aduana dos países de fronteira em um mesmo lugar: é preciso simplificar e unificar o processo, na medida do possível (NOGUEIRA, 2007; ADUANA BRASIL, 2012).

Um segundo desafio à territorialização se observa no desacordo sobre as taxas de câmbio e suas consequências para os moradores da região. Muitos são refratários às po- 
líticas de integração no MERCOSUL pelo efeito devastador sobre os agentes econômicos locais. Mudanças na política cambial de cada país causa uma atribuição de valor problemática, e gera diferenças no preço final dos produtos em áreas de fronteira. Enquanto o MERCOSUL não estabelecer marcos mais precisos para uma política cambial da instituição, haverá corrida de turistas e moradores da região para aproveitar os melhores preços de um dos lados das fronteiras. Nesse processo, a territorialização de políticas culturais e, sobretudo, de serviços de apoio e da iniciativa privada se apresenta por meio de um quadro de instabilidade e de cautela por parte dos investidores.

Um terceiro desafio significativo se apresenta mediante conflitos entre guaranis e "gaúchos" na área de fronteira. Tais conflitos são reconhecidamente antigos e dificultam a concepção de uma política cultural integrada. Toda a ocupação dessa área foi constituída por um embate contínuo que envolvia Estados, etnias, fazendeiros, diferentes tribos, ordens religiosas, entre outros aspectos. Na atualidade a alta taxa de mortalidade, de 100 em cada grupo de 100 mil habitantes, que se apresenta entre os grupos indígenas indica que os conflitos territoriais que se desenham entre gaúchos e guaranis não são apenas simbólicos, pois ainda são concretos e violentos. Ao contrário das inimizades, rivalidades e conflitos que se observavam na União Europeia, por exemplo, o MERCOSUL ainda não foi capaz de mediar soluções e acordos para pacificar a região, trazendo problemas para o turismo cultural que pretende desenvolver.

O recente manifesto de indígenas Guarani Kaiowás expõe esse conflito territorial de forma evidente, caracterizando a estética e o modo de vida gaúchos como parte de uma violência ainda maior:

"estes mesmos fazendeiros caracterizados de pistoleiros de 'faroeste/estilo gaúcho', já ricos em cima do sangue dos indígenas, retornaram a anunciar a morte coletiva guarani-kaiowá ou genocídio do povo guarani-kaiowá. Eles reafirmam que vão continuar matando os indígenas em nossos próprios territórios antigos." (GUARANI KAIOWÁ, 2012.)

Ainda mais clara, a Carta Final do II Encontro Guarani, que reuniu mais de mil lideranças indígenas guaranis, descarta a mediação que o MERCOSUL poderia estabelecer na consolidação do seu território. De acordo com essa visão, não é desejável ter as terras, valores, indivíduos e símbolos guaranis confundidos com outros ou integrados à lógica de um mercado comum. Tampouco os representantes pareceram tentados diante dos recursos ou da autonomia que poderia ser estabelecida a partir de uma das chancelas culturais do MERCOSUL, como ocorre com os itinerários culturais. É nesse sentido que a Carta Final expõe:

[resolvemos] "Que a Nação Guarani não formará parte da estrutura do MERCOSUL e que se abocará ao fortalecimento de suas organizações de base e ao Conselho Continental. O plenário discutiu a proposta inicial do I Encontro de criar uma instância em nível do mercado comum e decidiu por enquanto não dar curso à proposição." (NACIÓN GUARANI, 2012.) 
Nesse contexto, a territorialização dos itinerários culturais das Missões Jesuítico-Guaranis ainda se apresenta problemática pela forma como diferentes agentes locais produzem e qualificam os seus territórios. Diversas barreiras, simbólicas e/ou concretas, são erguidas para tentar influenciar ou até mesmo controlar o modo como esta área se representa em escala continental, interferindo no ritmo da implementação dessa política cultural. Como afirmou Vaz:

\begin{abstract}
“(...) tais temas eram contemplados no marco de reuniões especializadas e sem conexões claras com a agenda econômico-comercial. (...) Em segundo lugar, o tratamento dispensado a tais temas era definido a partir de avaliações que ressaltavam suas potencialidades, instrumentalidade ou desdobramentos eventuais do ponto de vista econômico e seus vínculos possíveis com o projeto de mercado comum, no longo prazo. (...) Em terceiro lugar, as agendas nas áreas ora consideradas mantinham-se desarticuladas em grande medida, possuindo como referências comuns o sentido político atribuído à integração regional, por extensão ao MERCOSUL, o objetivo último de estabelecimento de um mercado comum. Talvez por decorrência desta característica, os resultados alcançados, até o momento, sejam pouco palpáveis (o que não encerra nenhum juízo necessário sobre sua relevância e alcance) ou de longa maturação." (VAZ, 2003: p. 30-31.)
\end{abstract}

\title{
Os riscos da territorialização dos itinerários culturais
}

Dois riscos devem ser mencionados a respeito da territorialização incompleta de um itinerário cultural. O primeiro desses riscos é aquele representado por um certo tipo de historicismo. Para garantir a autenticidade do itinerário e evitar que o território seja transformado física e simbolicamente, o comitê gestor definiria os limites de um itinerário fixo, seguindo as bases de um rigor histórico que não contemplasse nenhum outro tipo de conexão com o presente que não fosse pelo reconhecimento do valor cultural e econômico da exploração de suas ruínas e de suas línguas.

Nesse processo, a defesa desse patrimônio material e imaterial oriundo passado por vezes ignora a vida cotidiana contemporânea e as próprias lideranças locais que poderiam servir de ponte entre os agentes do Estado, os organismos internacionais de fomento às políticas culturais e a população local. Nogueira (2007), entre outros, argumenta que um dos principais problemas para a implementação da política cultural do MERCOSUL é justamente a falta de recursos humanos preparados para o turismo e a conservação, além do desconhecimento da população acerca do patrimônio. O desinteresse e o desconhecimento da população local sobre as culturas guaranis ou sobre as missões jesuíticas e suas reduções revela os desafios de se valorizar e qualificar um território de uma narrativa histórica distante, cujos símbolos e formas não se revelam significativos diante da vida cotidiana. Dentro desse contexto, a deterioração do patrimônio costuma ser mais rápida e o desenvolvimento de serviços e indústrias culturais são menos significativas. Do ponto de vista estritamente social e local, impor a conservação de uma forma passada de vida pode apresentar um risco de uma rejeição da população local à política patrimonial e seus objetos. 
O segundo risco da territorialização nos itinerários culturais das Missões Jesuíticas-Guaranis é aquele que se refere à tecnificação e exploração econômica plena da área a partir das indústrias culturais. Trata-se de um risco do presente: confiar na regularidade do turismo, no valor em si mesmo dos serviços especializados de transporte e de hotelaria, na modernização das atividades de lazer e na transformação do artesanato em uma atividade industrial eficiente do ponto de vista econômico. O risco se encontra tanto na perda da autenticidade do patrimônio quanto na desconexão com a vida cotidiana. Tais perdas geram uma sensação de artificialidade na vivência desse território, o que pode, a médio prazo, diminuir o interesse na visitação ou esvaziar os fóruns públicos locais que tentariam converter esse ganho econômico em benefícios sociais.

Como afirmou Capel, acerca das consequências das políticas de conservação:

"Un peligro grave que existe después de las designaciones de un bien o de un lugar como Patrimonio de la Humanidad es la presión de todo tipo a que se ven sometidos los espacios así calificados. Si los riesgos que suponen la llegada de un turismo masivo son importantes, más deletéreos son las que proceden del sector inmobiliario, que puede iniciar políticas desmesuradas de intervención, en busca de una rápida ganancia, y que conducen a la construcción de hoteles, de residencias y de equipamientos de ocio diversos, produciendo una densificación y, finalmente, un cambio irreversible del paisaje. Por ello la UNESCO y las instituciones gubernamentales deberían tener mecanismos para asegurar la protección y penalizar a aquellas comunidades que no cuidan debidamente del patrimonio que ha sido calificado y cuya salvaguardia les está encomendada. Lo que está sucediendo recientemente en la ciudad de La Laguna, después de su designación como Patrimonio de la Humanidad, debería ser una llamada de atención en ese sentido de dar lugar a las correcciones urgentes que se necesitan y las sanciones oportunas a técnicos y políticos tan poco sensibles a los valores históricos que habrían esforzarse en tutelar y conservar." (CAPEL, 2005.)

Em ambos os riscos, nota-se a falta de flexibilidade do território, convertido em uma área própria a outros, com discurso único, símbolos distantes ou artificiais e valores externos à população local. O controle do acesso e as apropriações simbólicas dessa área seriam geridos por poderes distantes do dia a dia da população. Uma via diferente de territorialização exigiria uma ação mais coordenada e sistemática de aproximação dos diferentes grupos locais, além de serviços mais regulares. O desafio ainda em curso da territorialização dos itinerários culturais Jesuíticos-Guaranis nos apresenta então um verificação experimental das reais possibilidades de integração cultural do MERCOSUL.

\section{REFERÊNCIAS BibLIOGRAFICAS}

ADUANA BRASIL. Mercovia S.A. — Primeiro Centro Unificado de Fronteira do MERCOSUL. Revista Aduana Brasil no 17, p. 14-15, 2007.

CAPEL, Horacio. Las rutas culturales como patrimônio de la humanidad: el caso de las fortificaciones americanas del Pacifico. Biblio 3w - Revista Bibliográfica de Geografía y Ciencias Sociales, v. X, no 562, 2005. Disponível em: <http://www.ub.es/geocrit/b3w-562.htm> Acesso em: jul./2012. GOMES, Paulo Cesar da Costa. A dimensão ontológica do território no debate da cidadania: o exemplo canadense. Território, v. 1, nำ 2, p. 43-62, 1997. 
GUARANI KAIOWÁS. Nota da Aty Guasu Guarani-Kaiowá às autoridades federais do Brasil e do Mundo diante da ameaça de morte coletiva indígena. Disponível em: <http://www.dhescbrasil.org.br/ index.php?option=com_content $\&$ view=article $\&$ id $=629$ :nota-guarani-kaiowa-ameaca-de-morte-coletiva\&catid=69:antiga-rok-stories> Acesso em: 15.set./2012.

HAESBAERT, Rogério. Território e Multiterritorialidade: Um Debate. GEOgraphia, Ano IX, no 17 p. 19-46, 2007.

ICOMOS. Carta de Itinerarios Culturales. Disponível em: <http://www.international.icomos.org/ charters/culturalroutes_sp.pdf> Acesso em: 17.set./2012.

MERCOSUL/CMC. Decisão n. 11/2006 - Sede Permanente do MERCOSUL Cultural. Disponível em: <http://www.mercosur.int/msweb/SM/Actas\%20TEMPORARIAS/ GMC/XXXI\%20GMC\%20 EXT/PDEC\%2011-06-SedeMCSCultural-PT.pdf> Acesso em: 30.ago./2012.

MERCOSULCMC.Decisãon. 11/1996 — Protocolo de integração cultural do MERCOSUL. Disponível em:<http://www.mercosur.int/msweb/Normas/Tratado\%20e\%20Protocolos/Dec_011_096_Prot\%20 Integra\%C3\%A7\%C3\%A3o\%20Cultural\%20MCS_Ata\%202_96.pdf> Acesso em: 01.ago./2012.

NACIÓN GUARANI. Carta Final do II Encontro da Nação Guarani. Disponível em: <http://www. cimi.org.br/site/pt-br/index.php?system=news\&action=read\&id=5414> Acesso em: 15.set./2012. NEGRETE, Ângela Sanchez. A cultura nas Missões Jesuítico-Guaranis. In: MAGTER, MARY MABEL PELLIZZER (org.) Circuito Internacional Misiones Jesuitico Guaranies. Posadas: UNAM, 2005.

NOGUEIRA, Carmem Regina Dornelles. Oturismo, o reencontro e a redescoberta da Região das Missões. Tese de Doutorado em Geografia Humana, FFLCH-USP, 2007.

PESAVENTO, Sandra Jotahy. Missões, um espaço no tempo: paisagens da memória. In: PESAVENTO, SANDRAJOTAHY; MEIRA, ANA LUCIA GOELZER (Orgs.). Fronteiras do Mundo Ibérico: Patrimônio, território, e memória das Missões. IPHAN. Porto Alegre: UFRGS Editora, 2007.

SACK, Robert David. Human territoriality — its theory and its history. Cambridge: Cambridge University Press, 1986.

UNESCO. Anteproyecto de Itinerarios Culturales del Mercosur. Disponível em: <http://www.unesco.org. uy/ci/fileadmin/cultura/Anteproyecto\%20Itinerarios\%20Mercosur\%20-\%20Espa\%C3\%B1ol\%20 correc270109.d\%E2\%80\%A6.pdf> Acesso em: 01.set./2012.

VALVERDE, Rodrigo Ramos Hospodar Felippe. Transformações no conceito de território: competição e mobilidade na cidade. GEOUSP, nํ15, p. 119-126, 2004.

VAZ, Alcides Costa. Mercosul: educação, justiça, cultura e desenvolvimento social em perspectiva. In: ALVARÉZ, GABRIEL; FURTADO, CELSO (orgs.). Indústrias Culturais no MERCOSUL. IBRI, 2003. 